\title{
Effect of surfactants and their blend with silica nanoparticles on wax deposition in a Malaysian crude oil
}

\author{
Zhen Hao Lim $^{1} \cdot$ Hikmat Said Al Salim ${ }^{1} \cdot$ Norida Ridzuan $^{2} \cdot$ Ronald Nguele $^{3} \cdot$ Kyuro Sasaki $^{3}$
}

Received: 13 March 2018/Published online: 10 July 2018

(C) The Author(s) 2018

\begin{abstract}
The present study investigated the wax deposition tendencies of a light Malaysian crude oil $\left(42.4^{\circ}\right.$ API), and the wax inhibiting potential of some surfactants and their blends with nanoparticles. With the knowledge that the majority of the wax inhibition research revolved around polymeric wax inhibitors, which cause environmental issues, we highlighted the potential of surfactants and their blend with $\mathrm{SiO}_{2}$ nanoparticles as wax deposition inhibitors. Different surfactants including oil-based, silane-based, Gemini and bio-surfactants were considered as primary surfactants. The primary surfactants and their respective blends at a concentration of $400 \mathrm{ppm}$ were screened as wax inhibitor candidates using cold finger apparatus. The screening results showed a significant influence on the paraffin inhibition efficiency on wax deposition by using $400 \mathrm{ppm}$ of silane-based surfactant, which decreased the wax deposition up to $53.9 \%$ as compared to that of the untreated crude oil. The inhibition efficiency among the silane-based surfactant (highest) and bio-surfactant (lowest) revealed an appreciable difference up to $36.5 \%$. Furthermore, the wax from the treated sample was found to deposit in a thin gel-like form, which adhered inadequately to the surface of the cold finger. A further investigation by blending the $400 \mathrm{ppm}$ silane-based surfactant with a $400 \mathrm{ppm} \mathrm{SiO}_{2}$ nanoparticle suspension in a load ratio of 3:1 found that the wax inhibition decreased up to $81 \%$ as compared to the scenario when they were not added. However, we have shown that the synergy between the silane-based surfactant and the nanoparticles is influenced by the concentration and load ratio of surfactant and nanoparticles, residence time, differential temperature and rotation rate.
\end{abstract}

Keywords Cold finger - Nanoparticles · Wax deposition - Wax inhibitor · Surfactant · Wax appearance temperature

\section{Introduction}

With the decline in conventional oil resources, the production of unconventional oils, such as waxy crude and heavy crude oils, has increased ( $\mathrm{Li}$ et al. 2015). Approximately, $20 \%$ of the world oil reserves are waxy crude oil and half of the recoverable oil reserves are heavy crude oil

Edited by Yan-Hua Sun

Zhen Hao Lim

billylim0610@gmail.com

1 Department of Chemical and Petroleum Engineering, UCSI University, 56000 Cheras, Kuala Lumpur, Malaysia

2 Faculty of Chemical and Natural Resources Engineering, Universiti Malaysia Pahang, Lebuhraya Tun Razak, 26300 Kuantan, Malaysia

3 Resource Production and Safety Engineering Laboratory, Kyushu University, Fukuoka 819-0395, Japan
(Ghannam et al. 2012; Kumar et al. 2015). One of the frequently encountered problems in unconventional oils is the presence of high paraffin wax content (Lira-Galeana and Hammami 2000). Precipitation and deposition of wax on the walls of production pipelines begin when the temperature of bulk oil falls below its wax appearance temperature (WAT). During the transportation of crude oil in the subsea region, where the average temperature can be as low as $5{ }^{\circ} \mathrm{C}$ near the seabed, the liquid-phase waxy crude oil undergoes three phase changes (Chala et al. 2018). With the change in the operating conditions (temperature and/or pressure), the wax particles aggregate within the cluster (Ganeeva et al. 2016). When the size of the clusters is large enough, the wax precipitates. The last stage is the gelation of a wax layer, whereby the wax molecules constantly deposit layer-wise and finally lead to a clogging gel that may result in a complete shutdown of production pipeline systems. Therefore, managing wax precipitation and 
deposition in production has become a major challenge in the oil and gas industry.

Various methods to address the precipitation and deposition of waxes have been proposed theoretically and applied in practice. However, among these methods, the use of polymeric pour point depressant (PPD) is the emerging and convenient method. Generally, the polymeric PPDs are mainly used (1) to reduce the WAT and pour point (PP), (2) to improve the rheological properties of waxy crude oil and most importantly (3) to modify its wax crystal structure which prevents its aggregation. Various modifications of PPDs were examined by Wang et al. (2011), Yang et al. (2015) and Song et al. (2016) on polymeric PPDs, such as introducing nanomaterials to the polymeric PPDs to enhance their performance, and it was confirmed that the polymeric nanohybrids provided a large amount of nucleation sites with interfaces which provide spherical-like templates upon which wax molecules can precipitate. The altered morphology of crystals to spherical shape helps in decreasing the WAT, gelation temperature and rheological behaviour. Several possible mechanisms that may account for the improved performance with nanoparticles were reported by Wang et al. (2011). These include dispersed nucleation, the ability to partition into the wax crystal structure and adsorption onto wax crystal surfaces. It appears that the modification of PPDs has received a lot of attention in the area of waxy crude oil research due to its ability to improve the efficiency of the polymers' properties. The latter case is the scope of this work with a focus on the synergy between surfactant and nanomaterials with a further purpose to prevent the wax deposition in a more cost-effective way.

Surfactants have been widely investigated to improve the flow properties of waxy crude oil by reducing the WAT. However, there are very few studies made on wax deposition inhibition when compared to the WAT studies by polymeric PPDs. Surfactants are effective in preventing wax deposition by producing an inhibition environment to lower the adhesion of waxes to the cold pipe walls (Wang et al. 2016). The molecules of surfactant alter the wettability of the pipe surfaces and then adsorb onto the pipe surfaces, thus constraining the wax deposition by allowing those wax crystals to be easily sheared off (Maithufi et al. 2011). Besides, the stabilization of the formation of oil in water $(\mathrm{O} / \mathrm{W})$ emulsion by surfactant prevents paraffin crystals from depositing and agglomerating too. The mechanism of surfactant action was found to be similar to that of the polymeric PPD which has the co-crystallizing ability of the polar tails which partition onto the wax crystals, followed by their ability to alter the crystal morphology (Banerjee et al. 2015). As a result, the pour point and the size of crystals formed are reduced. Apart from that the adsorption and adhesion of surfactant molecules on the surface of growing wax particles further inhibit their growth and their micelle cores alter the wax crystal habits. Moreover, the conventional polymeric PPDs usually have high molecular weight, long polymer chains, and high thermostability. Thus, it is a challenging process to decompose these chemicals in the refinery system, rendering them environmentally, unfriendly and costly. In this case, the surfactants used in this study could potentially act as cleaner and cheaper additives for crude oil with lower molecular weight and smaller molecules (Kumar and Mahto 2017; Gu et al. 2018).

The emergence of the use of nanotechnology in the petroleum industry and the benefits of surfactants have captured the interest of authors to study different types of surfactants and their impacts after the addition of nanoparticles which may potentially act as wax deposition inhibitors. However, the effects of combining of surfactants and nanoparticles as wax inhibitor on the wax deposition are unclear, and studies on this aspect are limited. Therefore, our study focuses on determining the most effective surfactant with (and without) nanoparticles in order to minimize the wax deposits. In addition, our study is extended to cover the possible dominant factors such as the differential temperature, residence time, rotation rate and the concentration of inhibitors that might govern wax deposition.

\section{Experimental}

\subsection{Materials}

Five different surfactants were used as wax inhibitors in this research. Their respective properties are outlined in Table 1 and their chemical formulas are depicted in Fig. 1.

S1 was supplied by Malaysian Palm Oil Board (Bangi, Malaysia), whereas S2 and S3 were received from RunHe Co. Ltd (Hangzhou, China). S4 was purchased from Iota Co. Ltd (Anhui, China) and S5 was synthesized and supplied by Lion Corporation (Tokyo, Japan). The synergistic study of the primary surfactants and nanoparticles was performed using silica-based nanoparticles $\left(\mathrm{SiO}_{2}\right)$ supplied by Tecnan (Tokyo, Japan). The nanoparticles have an average particle size of $10-15 \mathrm{~nm}$ measured by X-ray diffraction.

The light crude oil sample was generously supplied by PETRONAS Kertih Refinery (Terengganu, Malaysia). The properties of the crude oil are outlined in Table 2. 
Table 1 Properties of primary surfactants

\begin{tabular}{llc}
\hline Surfactant name & Type & Classification \\
\hline Sophorolipid & Bio-surfactant & Code \\
3-octyl-hepta-methyl trisiloxane & Silane-based surfactant & Non-ionic \\
3-2-methoxyethoxy propyl-methyl-bis trimethylsilyloxy silane & & S2 \\
2-methoxy(polyethyleneoxy)propyl heptamethyltrisiloxane & & N3 \\
Trimethylene-1,3-bis hexadecyl dimethylammonium bromide & Gemini surfactant & Non-ionic \\
\hline
\end{tabular}<smiles>CCOC1OC(COC(C)=O)C(O)C(O)C1OC1OC(COC(C)=O)C(O)C(O)C1O</smiles>

(a) $\mathrm{S} 1$<smiles>COCOCCC[Si](C)(O[Si](C)(C)C)O[Si](C)(C)C</smiles>

(c) $\mathrm{s} 3$<smiles>C[N+](C)(C)CCC[N+](C)(C)Br</smiles>

(e) $\mathrm{S5}$<smiles>C[Si](C)(C)O[Si](C)(C)O[Si](C)(C)C</smiles>

(b) $s 2$

Fig. 1 Chemical structures of investigated surfactants

Table 2 Properties of investigated light crude oil

\begin{tabular}{lcl}
\hline Physiochemical properties & Value & Test instruments \\
\hline Wax appearance temperature, ${ }^{\circ} \mathrm{C}$ & 21.9 & Differential scanning calorimeter \\
Pour point, ${ }^{\circ} \mathrm{C}$ & 13.0 & ASTM D97-17b \\
Viscosity at $20{ }^{\circ} \mathrm{C}, \mathrm{MPa} / \mathrm{s}$ & 6.15 & ASTM D445-06 \\
Oil gravity, ${ }^{\circ}$ API & 42.4 & AccuPyc II 1340 series pycnometer \\
Surface tension, $\mathrm{mN} / \mathrm{m}$ & 23.0 & Du Noüy ring tensiometer \\
Wax content, $\%$ & 8.22 & Modified UOP $46-64$ \\
Asphaltene content, wt $\%$ & 0.65 & ASTM D2007-80 \\
\hline
\end{tabular}




\subsection{Preparation of surfactants, $\mathrm{SiO}_{2}$ nanofluids and surfactant/particle (SN) blends}

$0.8 \mathrm{~mL}$ (or the equivalent amount) of surfactant (stock solution) was dissolved in $100 \mathrm{~mL}$ of deionized water to form $400 \mathrm{ppm}$ of surfactant (diluted solution). The solution was stirred at $700 \mathrm{rpm}$ for $1 \mathrm{~h}$ to form a stable homogenous solution. To prepare $400 \mathrm{ppm}$ of $\mathrm{SiO}_{2}$ nanofluid, $40 \mathrm{mg}$ of $\mathrm{SiO}_{2}$ nanoparticles were weighed and mixed with $100 \mathrm{~mL}$ of xylene (which is used in this study as a base fluid). The mixture was heated to $80^{\circ} \mathrm{C}$ and stirred at $400 \mathrm{rpm}$ for $1 \mathrm{~h}$, and the procedure was followed by ultrasonication treatment (Ultrasonic bath FB15051, Fisherbrand) for another $30 \mathrm{~min}$ at $25{ }^{\circ} \mathrm{C}$. To prepare the surfactant/nanoparticles (SN) blends, surfactant and nanoparticles in a load ratio of $3: 1$, that is $3 \mathrm{wt} \%$ of the $400 \mathrm{ppm}$ surfactants $(7.51 \mathrm{~g})$, were blended with $1 \mathrm{wt} \%$ of the $400 \mathrm{ppm}$ nanofluids $(2.50 \mathrm{~g})$. The amount of the surfactants and nanoparticles (wt\%) added into the crude oil samples was constant with respect to the total mass of crude oil in each run $(300 \mathrm{~mL}=250.3 \mathrm{~g})$. The surfactant/nanoparticle blend was stirred at $25{ }^{\circ} \mathrm{C}$ for $1 \mathrm{~h}$ prior to injecting into the vessel.

\subsection{Cold finger apparatus}

The cold finger method is a common experimental set-up used in this field to simulate and analyse wax deposition by mimicking the subsea condition when warm oil comes in contact with the cold pipe wall (Jennings and Weispfennig 2005). The cold finger equipment was used to study the wax deposition on Malaysian light crude oil based on various conditions (Fig. 2).

The crude oil samples $(300 \mathrm{~mL})$ were conditioned above the WAT via thermal treatment in an oven for $1 \mathrm{~h}$ to solubilize the precipitated wax and to eliminate any thermal history before inserting it into the stainless steel vessel. Throughout the wax inhibitor screening stage, the crude oil sample was controlled at a constant temperature of $53{ }^{\circ} \mathrm{C}$, representative of crude oil at the borehole and a cold finger temperature of $7{ }^{\circ} \mathrm{C}$ which represents the temperature near the seabed. The impeller rotation rate was set at $200 \mathrm{rpm}$ initially, and the experiment was performed for $2 \mathrm{~h}$ to simulate the shear flow and the ageing effect. The impeller rate was subsequently increased to 400 and $600 \mathrm{rpm}$. The investigated surfactant (or its respective blend) with a concentration of $400 \mathrm{ppm}$ was injected into the vessel for every run. At the end of each run, the deposited wax was collected from the cold finger. Each batch of experiment was repeated three times and the results were averaged. Paraffin inhibition efficiency (PIE) was then evaluated as suggested by Bello et al. (2006),
$\mathrm{PIE}=\frac{W_{\mathrm{f}}-W_{\mathrm{t}}}{W_{\mathrm{f}}} \times 100$

where PIE is the paraffin inhibition efficiency (in $\%), W_{\mathrm{f}}$ is the amount of wax deposition before the treatment of wax inhibitor (in g) and $W_{\mathrm{t}}$ is the amount of post-wax inhibitor treatment (in g).

\section{Results and discussion}

\subsection{Screening stage of wax inhibitors}

\subsubsection{Using pure surfactants}

Figure 3 shows the amount of wax deposits obtained using five different surfactants.

The blank crude oil (control experiment) was compared with five different surfactant-treated crude oils at a concentration of $400 \mathrm{ppm}$ to observe the difference in the amount of wax deposits. The wax deposited by blank crude oil was $1.45 \mathrm{~g}$, and the amount of wax deposits was successfully reduced to $1.19,0.94,0.66,0.70$ and $0.79 \mathrm{~g}$, respectively, by S1, S2, S3, S4 and S5. Significantly, this is equivalent to the PIE from a scale of $100 \%$ to $17.4 \%$, $34.9 \%, 53.9 \%, 51.2 \%$ and $45.6 \%$, respectively. The order of wax inhibitor performance is listed in the following sequence in descending order: S3 $>\mathrm{S} 4>\mathrm{S} 5>\mathrm{S} 2>\mathrm{S} 1$.

These primary observations revealed that the least wax was deposited from S3 as a result of the unusual wetting ability and solvent characteristics of the trisiloxane. This is due to (1) the super-wetting ability of S3 and hydrophilicity brought about by the high content of alkylene oxide in the polyalkylenoxy groups, (2) the dispersed particles are associated with formation of very thick wetting films during high rates of spreading which in turn provided an environment to inhibit the wax deposition and (3) the ability of trisiloxane to perform as a cleaning agent to detach oil droplets and films from surfaces as reported by Churaev et al. (2001), which is suggested as a similar mechanism occurred in our study for wax deposition removal. Apart from that, Wang et al. (2016) showed that the polar moieties of the surfactant tend to absorb into the wax crystal to reduce the wax crystal size and prevent agglomeration.

These results have proven that the use of surfactants has the ability to modify the surface of the wax deposition layer and control the rigidity, adhesive ability or the amount of wax deposits by modifying the crystal structure itself. It is confirmed that all the surfactants used in this study have managed to prevent wax deposition at an adequate scale. The functional groups and the wetting ability of each 


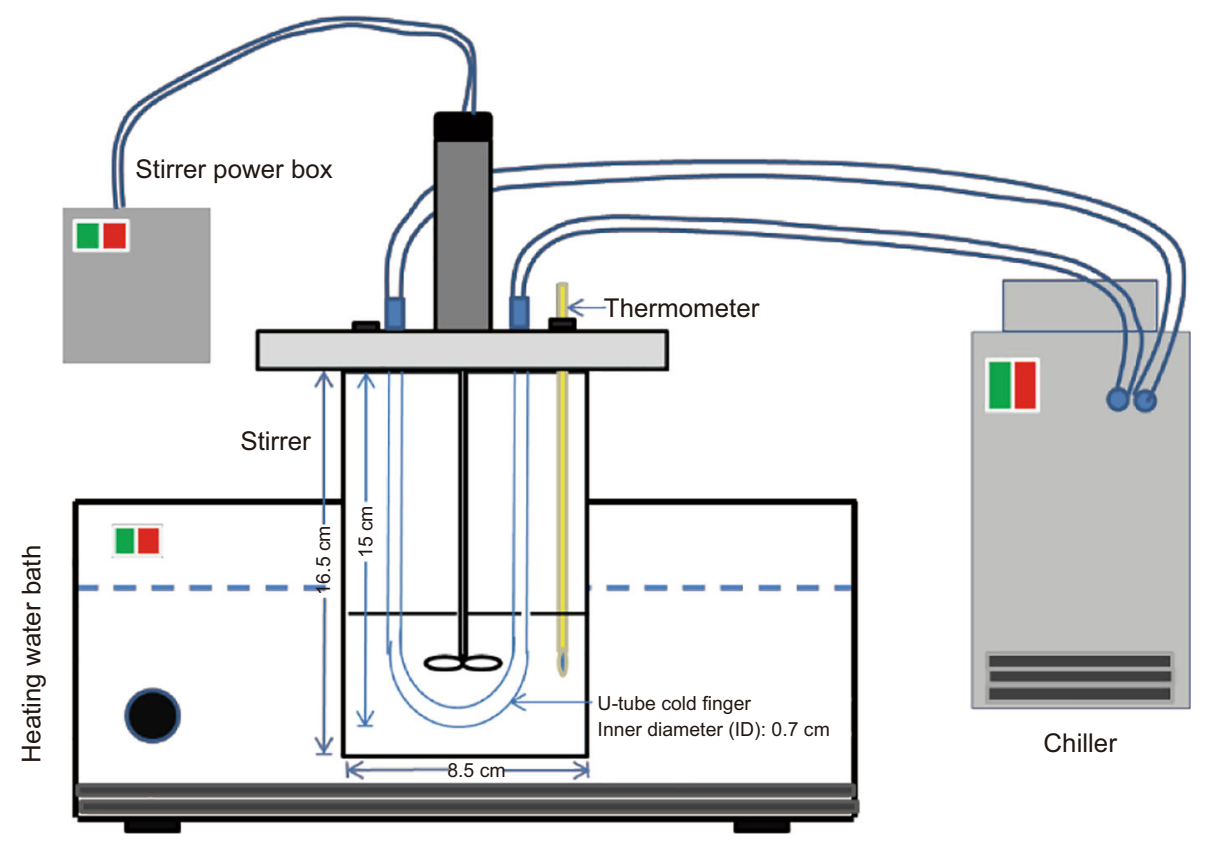

Fig. 2 Cold finger apparatus set-up (Ridzuan et al. 2016a)

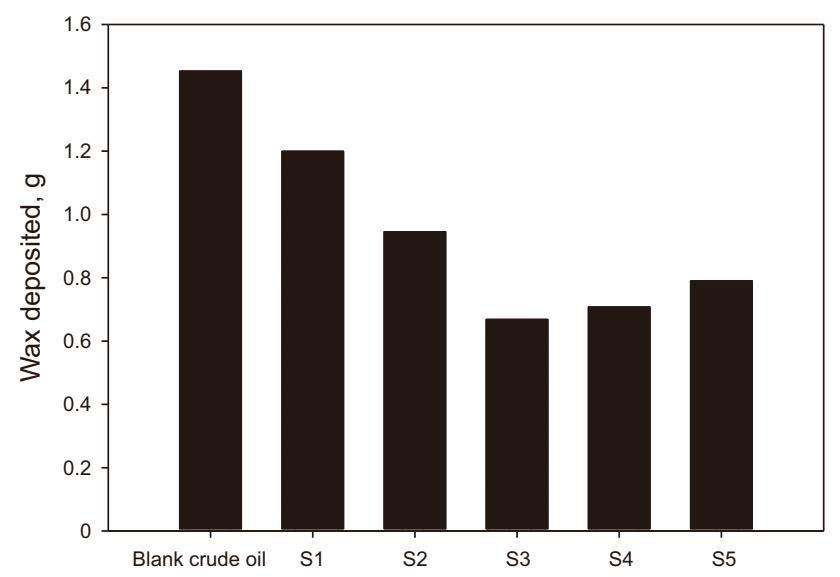

Fig. 3 Performance of wax inhibitors on wax deposition using only surfactants

surfactant in this study are the keys to differentiate their inhibition efficiency.

\subsubsection{Using blended surfactants}

Figure 4 shows the amount of wax deposits obtained using five different blended surfactants.

All the primary surfactants $(400 \mathrm{ppm})$ were blended with $\mathrm{SiO}_{2}$ nanoparticles (400 ppm) coded by SN1, SN2, SN3, SN4 and SN5. The results are shown in the following sequence in descending order: $\mathrm{SN} 3>\mathrm{SN} 4>\mathrm{SN} 2>$ SN1 $>$ SN5. Similarly, with blended surfactants, SN3 exhibited the highest efficiency while SN5 displayed the lowest efficiency. The amount of deposits from all SN-

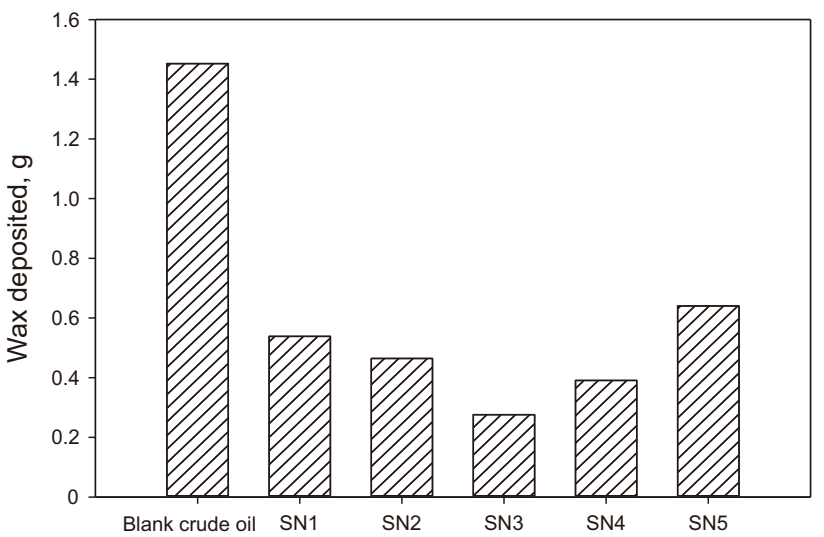

Fig. 4 Performance of blended surfactants on wax deposition

treated samples was successfully reduced to a lower level compared to that of the pure surfactant-treated samples. The amount of wax deposits reduced was recorded as 0.53 , $0.46,0.27,0.39$ and $0.64 \mathrm{~g}$ by SN1, SN2, SN3, SN4 and SN5, respectively. The PIE of SN3 increased from $53.9 \%$ to a remarkable $81 \%$ with the addition of $\mathrm{SiO}_{2}$ nanoparticles. It is notable that the performance of the least effective wax inhibitor, S1, was found to be enhanced unexpectedly from $17.4 \%$ to $63 \%$.

In this study, it is confirmed that the overall performance of primary surfactants improved with the addition of nanoparticles. The improvement could be attributed when the $\mathrm{SiO}_{2}$ nanoparticles associate themselves with surfactants, and the surfactant blends then behave as wetting agents, non-emulsifiers and surface tension reducers, which further enhance the removal of oil, wax and leaves the 
surface water wet. The majority of the nanohybrid wax inhibition studies were based on polymeric PPDs, and to date, the mechanism of nanohybrids involving surfactants is not adequately grasped. Nonetheless, it is proposed that both of them exhibit a similar mechanism which improved efficacy, thermal blendability and shear stability with the association of nanoparticles (in the surfactant). Generally, further work is required to elucidate the mechanism of surfactant/nanoparticle blends. Furthermore, the addition of $\mathrm{SiO}_{2}$ nanoparticles in this experiment may help in dispersing and stabilizing asphaltenes in the crude oil due to the nature of high adsorption affinity and large surface area of nanoparticles. This causes the asphaltenes and resins to be adsorbed on the surface of nanoparticles, thus preventing the aggregation of asphaltenes. The aggregated asphaltenes in crude oil could potentially serve as a nucleator for wax crystallization which leads to a severe fluidity problem with a higher WAT in the crude oil (García 2000; Lei et al. 2014; Song et al. 2016). With the reduction in asphaltene aggregation as well as the WAT, the wax crystallization could be hindered and hence also the wax deposition. Apart from that, the presence of surfactant in the emulsion is also necessary to functionalize the surface of nanoparticles and improve their adsorption.

\subsubsection{Comparison between surfactants and blended surfactants}

Figure 5 shows the differences in physical appearance of wax deposits obtained from blank and treated samples (400 ppm).

It was observed that the waxes that adhere on the cold finger surface from treated samples appeared seemingly softer in terms of rigidity (Fig. 5b) and less compact (Fig. 5c) when compared to the blank crude oil sample
(Fig. 5a). Industrially, an effective wax inhibitor is able to create weaker and softer deposits which are more susceptible to be sloughed off by shear forces in the flow field (Kelland 2014; Frigaard et al. 2017). The wax deposited from crude oil containing surfactant may have a lower molecular weight thus being softer and it is expected to be much easier to remove. It is believed that the main characteristics possessed by S3 which make it excellent when compared to all other surfactants are its extra stabilizing, wetting and super-spreading ability. Moreover, aqueous solutions of this surfactant spread rapidly over hydrophobic surfaces as a more preferable stabilizing agent. Its relatively low surface tension of $21 \mathrm{mN} / \mathrm{m}$ also helps to lower the surface tension at interfaces. The results, presented here, agree with the literature studies, which report that the addition of small amount of organic siloxanes to standard wax inhibitors reduces wax inhibition tremendously (Kelland 2014).

With 400 ppm of SN3 (Fig. 5c), the paraffin emulsion can be stabilized primarily due to the adsorption of surfactant molecules and nanoparticles on the surface of the wax particles. This is to say that both act as stabilizers (Koroleva et al. 2017). Emulsions, formed by the surfactant, are able to adsorb onto the bare production pipeline surface, making them oleophobic. As a result, the adhesion of wax decreases, improving the efficiency of corrosion inhibition (Wang et al. 2016). The protection layer may act as a nucleation site for wax deposition and if wax nucleation happens on the surfactant layer then the wax will not stick directly on the surface (Kelland 2014). Considering the results obtained in Fig. $5 \mathrm{c}$, it is rational to think that a similar mechanism occurred in our study. Table 3 summarizes the performance of S3 and SN3 on wax deposit reduction after adding $\mathrm{SiO}_{2}$ nanoparticles and performance of reported literature.
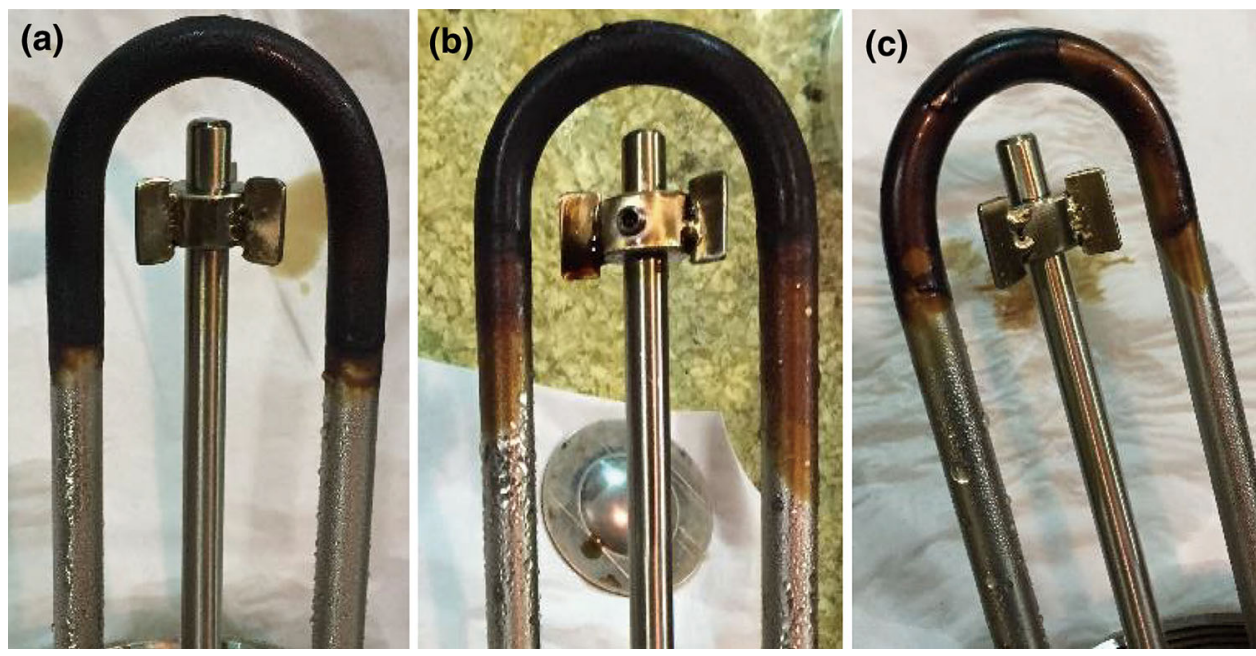

Fig. 5 Physical appearance of the deposited wax. a Blank sample, b S3-treated sample, c SN3-treated sample 
With reference to the results obtained in the screening stage by using S3 as wax inhibitor, a lower amount of wax deposit was collected from the cold finger. Since S3 and SN3 appeared as the most optimal wax inhibitor based on the amount of wax deposits and the PIE, we narrowed our study to only those two surfactants.

\subsection{Parameters altering the efficiency of wax inhibitors}

The choice of parameters was considered based on our previous research (Ridzuan et al. 2016a, b). However, we narrowed our selection to five parameters. These include the inhibitor concentration, surfactant-nanoparticles load ratio, the residence time, the temperature of cold finger and the rotation rate of the impeller.

\subsubsection{Effect of the concentration of wax inhibitors on wax deposition}

It is known that the compatibility of two potential wax inhibitors may exhibit synergistic or antagonistic effects on the properties of crude oil. Hence, further studies were carried out to determine the optimal combination of concentration in the selected wax inhibitor. The inhibition efficiency of Malaysian crude oil was investigated individually with 200, 400 and 1000 ppm of $\mathrm{S} 3$ and $\mathrm{SiO}_{2}$ nanoparticles in their blends. It was found that the incorporation of $400 \mathrm{ppm}$ of $\mathrm{S} 3$ and $200 \mathrm{ppm}$ of $\mathrm{SiO}_{2}$ nanoparticles provided an optimal wax deposition environment. Figure 6 shows the physical appearance of wax deposited from different combinations of concentration.

It was observed that the wax deposited from samples treated with 200 ppm of $\mathrm{SiO}_{2}$ nanoparticles in its blend had the thinnest layer and most brittle characteristic as compared to the sample treated with $1000 \mathrm{ppm}$ of $\mathrm{SiO}_{2}$ nanoparticles which was found to be in the hardened gel form. Whereas for S3, the rigidity of wax deposits and the amount of wax deposits were not able to be lowered by increasing the concentration to $1000 \mathrm{ppm}$. Hence, the maximum concentration suggested to mitigate the wax deposition in this case shall not exceed $400 \mathrm{ppm}$ for both $\mathrm{S} 3$ and $\mathrm{SiO}_{2}$. The observed physical appearance of wax deposited was in line with the data presented in Fig. 7.

A decrease in performance was noticed which offered PIE of $56.06 \%$ and $63.13 \%$ when the concentration of S3 was at its lowest (200 ppm) and highest (1000 ppm) in the $\mathrm{SN} 3$ blend. On the other hand, it is worth noting that with $200 \mathrm{ppm}$ of $\mathrm{SiO}_{2}$ nanoparticles, the PIE obtained was higher when compared to using $400 \mathrm{ppm}$ used in the screening stage (from $81 \%$ to $82.6 \%$ ), indicating the former as the optimal concentration for $\mathrm{SiO}_{2}$ nanoparticles. Besides, it is also noteworthy that the PIE does not change significantly with increase in $\mathrm{SiO}_{2}$ nanoparticle concentration $(1000 \mathrm{ppm})$. It is a fact that there is an optimum concentration dosage level and that a nanoparticle concentration of above 400 ppm does not increase the inhibition effect. This can possibly be due to these $\mathrm{SiO}_{2}$ nanoparticles acting as additional suspended particles and worsening the flow ability of crude oil which may eventually lead to a higher wax deposition. The results indicated that the amount of wax deposit decreases until a definite concentration is reached, above which the inhibition starts to deteriorate. The growth and thickening of wax deposits are determined by the concentration of wax inhibitor. Once the concentration reaches an optimum condition, it potentially changes the wax crystallization habit by providing more structures to interfere and merge with the edge of a growing wax crystal, thus impeding wax deposition. Apart from that, different concentrations of wax inhibitor may influence the van der Waals interaction between wax crystals in crude oil which predominantly determines the solubility of wax in crude oil (Machado and Lucas 1999).

Table 3 Difference in the amount of wax deposits and paraffin inhibition efficiency of treated crude oil

\begin{tabular}{lccc}
\hline Sample & Wax content, wt\% & Wax deposited, g & Paraffin inhibition efficiency PIE, \% \\
\hline This work & & & - \\
Blank crude oil & 8.22 & 1.45 & 53.9 \\
S3 & 8.22 & 0.66 & 81.0 \\
SN3 & 8.22 & 0.27 & 36.7 \\
Literature & & & 0.87 \\
Ethyl vinyl acetate & 20.6 & 31.9 & 29.1 \\
Maleic anhydride copolymer & 9.50 & & \\
\hline
\end{tabular}

${ }^{a}$ Reported by Ridzuan et al. (2016b)

${ }^{\mathrm{b}}$ Reported by Chi et al. (2016) 
(a)

Blank

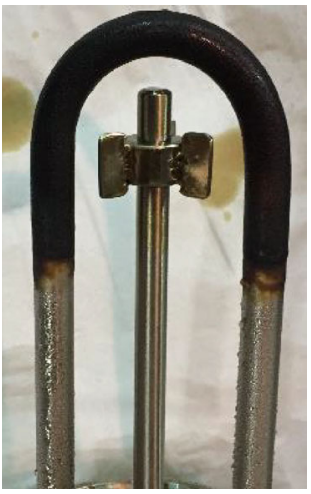

$C\left(\mathrm{SiO}_{2}\right)=200 \mathrm{ppm}$

$C(\mathrm{~S} 3)=400 \mathrm{ppm}$

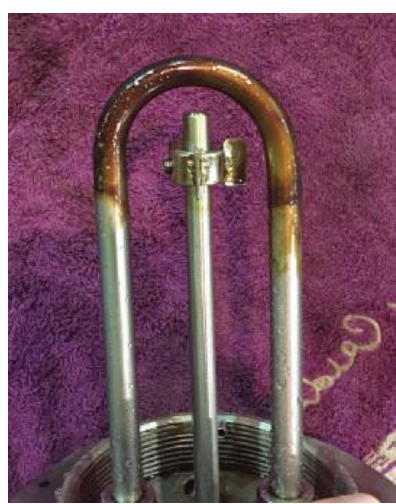

$C(\mathrm{~S} 3)=200 \mathrm{ppm}$

$C\left(\mathrm{SiO}_{2}\right)=400 \mathrm{ppm}$

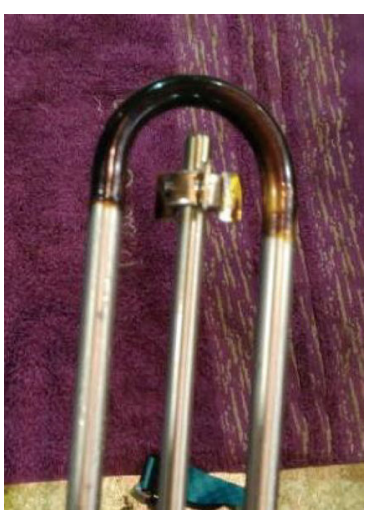

$C\left(\mathrm{SiO}_{2}\right)=400 \mathrm{ppm}$

$C(\mathrm{~S} 3)=400 \mathrm{ppm}$

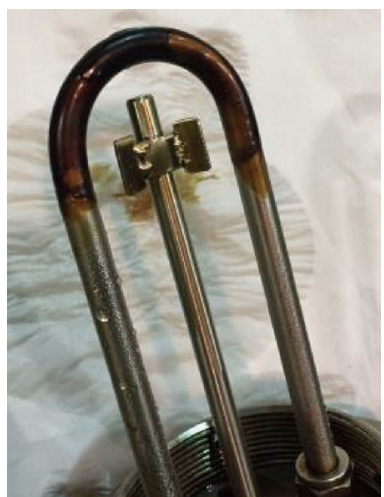

$C\left(\mathrm{SiO}_{2}\right)=1000 \mathrm{ppm}$

$C(\mathrm{~S} 3)=400 \mathrm{ppm}$

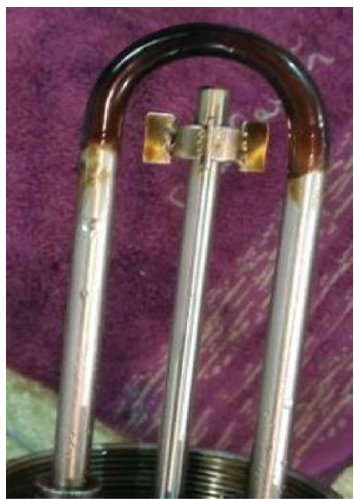

(b)

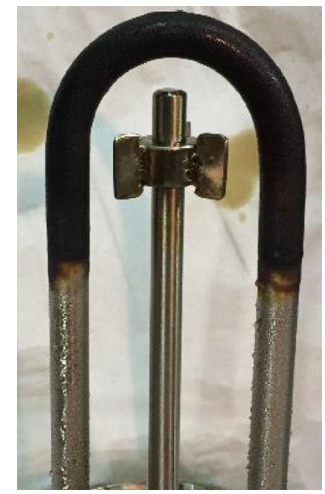

$C(\mathrm{~S} 3)=400 \mathrm{ppm}$

$\mathrm{C}\left(\mathrm{SiO}_{2}\right)=400 \mathrm{ppm}$

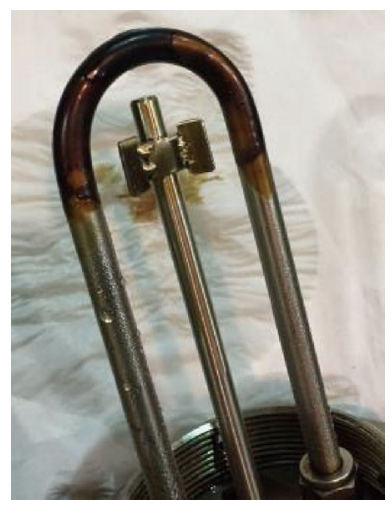

$C(\mathrm{~S} 3)=1000 \mathrm{ppm}$ $\mathrm{C}\left(\mathrm{SiO}_{2}\right)=400 \mathrm{ppm}$

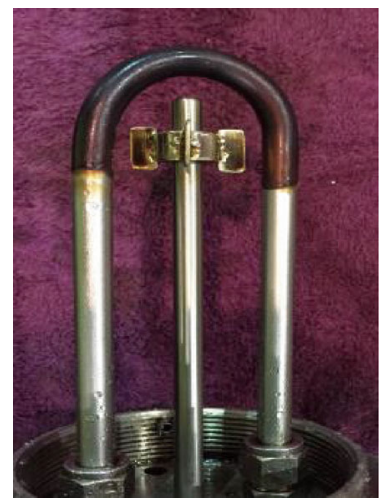

Fig. 6 Physical appearance of the deposited wax from treated crude oil at various concentrations. a Cold finger U-tube treated by SN3 with different concentrations of $\mathrm{SiO}_{2}$ nanoparticles, b Cold finger U-tube treated by SN3 with different $\mathrm{S} 3$ concentrations

(a)

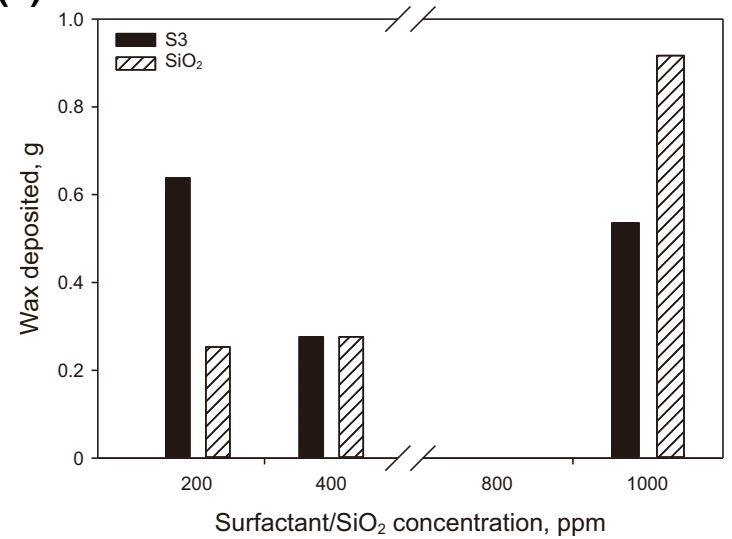

(b)

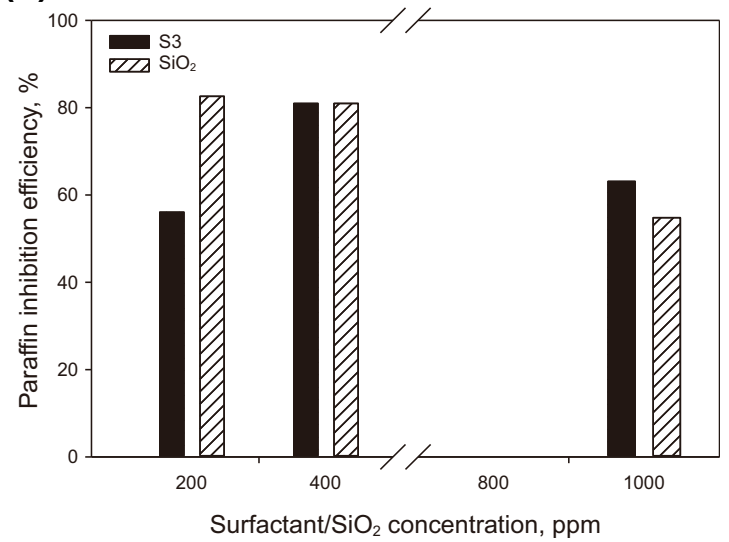

Fig. 7 Deposited wax and paraffin inhibition efficiency at different blend concentrations. a Deposited wax, b Paraffin inhibition efficiency 
Table 4 Total amount of wax inhibitor injected based on different load ratios

\begin{tabular}{lll}
\hline Mass, $\mathrm{g}^{\mathrm{a}}$ & & Load ratio, wt ${ }^{\mathrm{b}}$ \\
\hline Surfactant & Nanoparticles & \\
\hline 7.51 & 2.51 & $3: 1$ \\
5.00 & 5.00 & $1: 1$ \\
2.50 & 7.51 & $1: 3$ \\
\hline
\end{tabular}

${ }^{\mathrm{a}}$ Mass of wax inhibitor injected was measured based on the weight percentage listed with respect to mass of $300 \mathrm{~mL}$ of crude oil $(250.3 \mathrm{~g})$

${ }^{\mathrm{b}}$ Load ratio of surfactant to nanoparticles was determined based on the weight percentage

\subsubsection{Effect of the surfactant-nanoparticles load ratio on wax deposition}

For the purpose of investigating the effect of surfactantnanoparticles load ratio on wax deposition, different load ratios were used and the respective amounts are presented in Table 4. It can be observed in Fig. 8 that the wax deposited from SN3 with the highest surfactant ratio-treated sample appeared as the lightest, thinnest and least adhesive among the equal load ratio and the lowest surfactant ratio-treated sample, respectively. The equal load ratio-treated sample showed a thick and wet layer of wax, whereas the least surfactant ratio-treated sample was found in a dry and less compact condition.

Figure 9 shows the influence of surfactant-nanoparticles load ratio in SN3 on the PIE. It could be seen that SN3 with 3:1 load ratio offered the best performance in preventing the wax deposition on cold finger with a PIE of $81 \%$ $(0.27 \mathrm{~g})$ while the samples with a lower surfactant load ratio (1:1 and 1:3) had a lower PIE value of $56.6 \%(0.63 \mathrm{~g})$ and $61.7 \%(0.56 \mathrm{~g})$. The PIE of both lower surfactant ratio samples was close to each other. Hence, in this case, it is

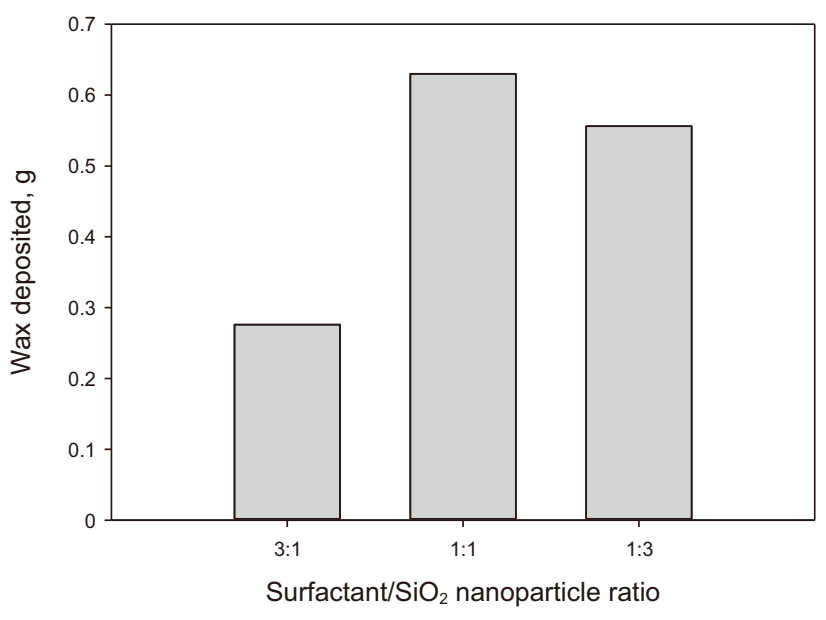

Fig. 9 Amount of wax deposits from SN3-treated samples at different load ratios

not suitable to decrease the wax deposits with a higher $\mathrm{SiO}_{2}$ nanoparticles load.

The phenomenon of a larger amount of wax deposit resulting from lower surfactant load ratio-treated samples (1:1 and 1:3) is aligned with the findings from Norrman et al. (2016) on investigating the effect of polymer coverage/nanoparticles on wax inhibition. In a similar situation, this is possibly caused by the aggregation of $\mathrm{SiO}_{2}$ nanoparticles and leads to inhomogeneity in samples which in turn causes wax in different parts of the sample to crystallize at different temperatures. Generally, it is confirmed that the addition of $\mathrm{SiO}_{2}$ nanoparticles is able to enhance the PIE of all primary surfactants, but only if in a favourable concentration and load. $\mathrm{SiO}_{2}$ nanoparticles on the other hand are known to complement the performances of S3 by improving the dispersion ability and solubility of wax. The role of wax dispersant is to prevent crystal aggregation by preventing the crystal nucleation phenomenon between crystal surfaces by absorbing itself onto
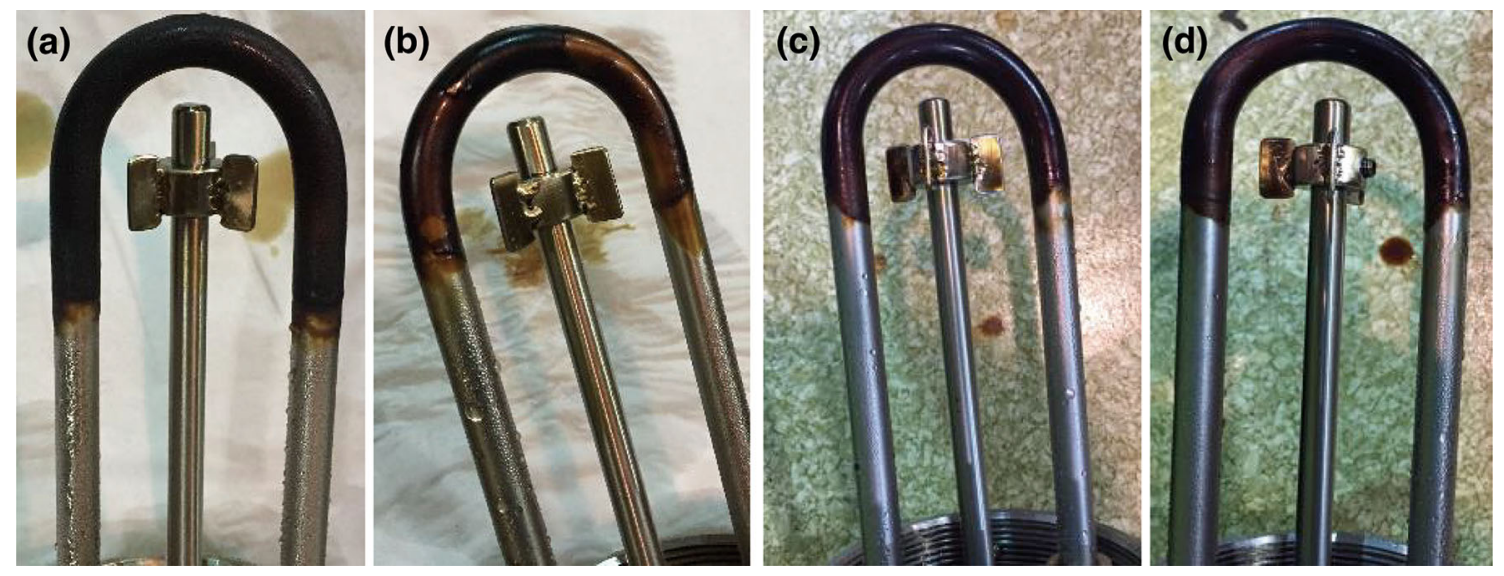

Fig. 8 Photographs of wax deposition on the cold finger U-tube at different load ratios. a Untreated U-tube, b 3:1 mass ratio, c 1:1 mass ratio, d 1:3 mass ratio 
the surface of the wax crystals. Thus, the synergetic behaviour between the surfactant and nanoparticles is thought to contribute to a higher PIE value in the higher surfactant ratio sample (Binks and Whitby 2005). This behaviour changed the hydrophobicity and flocculation of nanoparticles, thus enhanced the emulsion stability. When nanoparticles are coated with surfactant, the surfactant acts as a stabilizing agent to limit reaggregation and agglomeration of nanoparticles and therefore acts in reducing their sizes (Paramashivaiah and Rajashekhar 2016). Generally, it is crucial to find the optimum ratio of SN3 blend, and thus a load ratio of 3:1 can be taken as it offered the highest PIE.

\subsubsection{Effect of residence time on wax deposition}

Figure 10 compares the physical appearance of wax deposits from blank and SN3-treated samples after $15 \mathrm{~h}$. The wax deposited from blank crude oil was found to be thicker and more compact, while the SN3-treated sample was softer and easier to remove.

In this study, it is found that the amount of wax deposit and its rigidity increase as time increases from 2 to $15 \mathrm{~h}$. The amount increases due to the ageing effect in wax deposition. The wax deposited from both blank and SN3treated sample had the highest amount of wax deposits at $15 \mathrm{~h}$ for 1.81 and $1.14 \mathrm{~g}$ while the lowest at $2 \mathrm{~h}$ for 1.45 and $0.27 \mathrm{~g}$, respectively (Fig. 11).

Physically, the wax deposited on the cold finger after $15 \mathrm{~h}$ appeared to be more compact and in a hardened form (Fig. 10). This phenomenon happened due to the residence time, which is also known as wax "ageing". During the wax "ageing" process, there is a continuous diffusion of long-chain $n$-paraffin molecules from the bulk oil into the gel layer. The higher carbon number molecules diffuse into the deposited layer, while the lighter carbon number

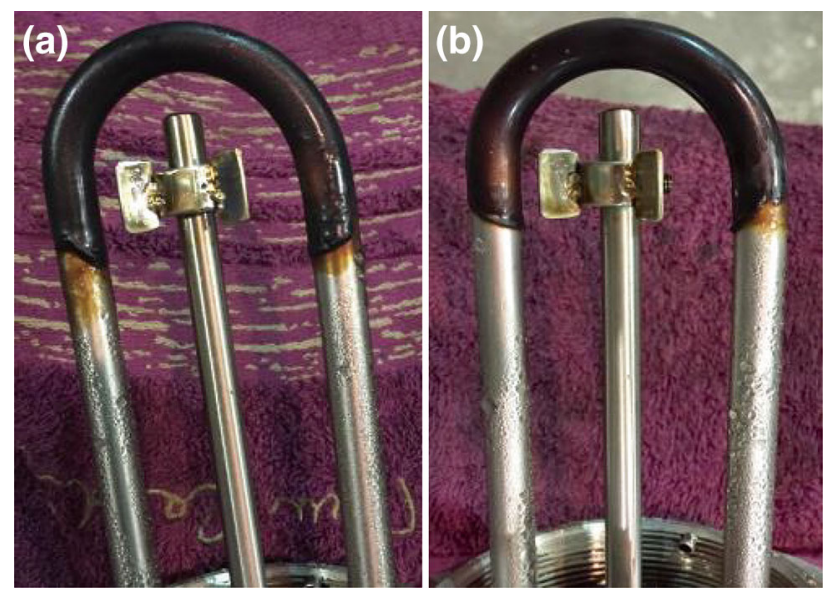

Fig. 10 Photographs of wax deposition on the cold finger after $15 \mathrm{~h}$ of treatment on both blank and SN3-treated samples. a Blank sample after $15 \mathrm{~h}, \mathbf{b}$ SN3-treated sample after $15 \mathrm{~h}$

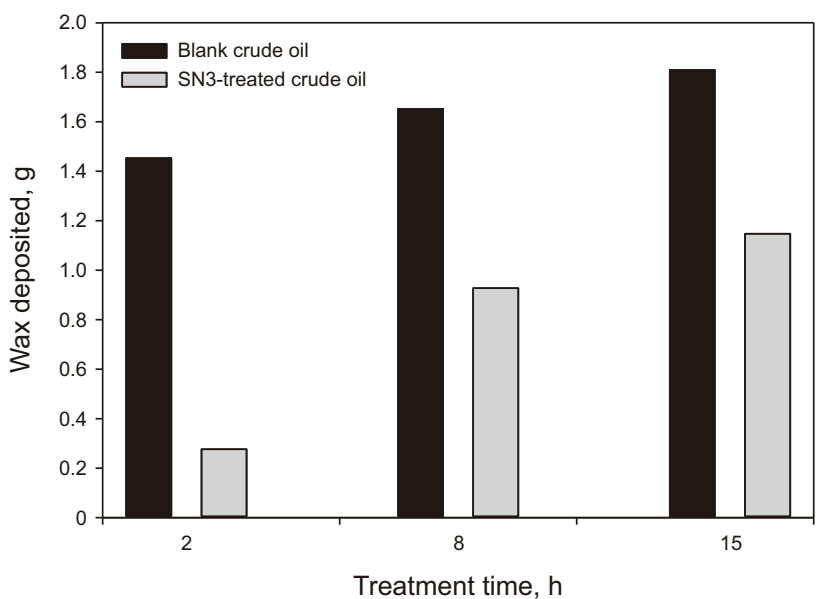

Fig. 11 Amount of wax deposits from blank and SN3-treated samples at different experimental durations

molecules diffuse in the opposite direction (Paso and Fogler 2003). Diffusion of these wax molecules into the gel deposit leads to a continuous precipitation of higher carbon number molecules within the gel matrix. Hence, this diffusion throughout the wax ageing process causes an increase in the solid-phase fraction of the deposits and forms a more rigid, compact deposits layer which hardens with increasing residence time (Quan et al. 2015).

Apart from that, it is worth noting that the amount of wax deposit especially in the SN3-treated sample increased significantly from 2 to $8 \mathrm{~h}$, then increased gradually from 8 to $15 \mathrm{~h}$. It is shown that the increment in the amount of wax deposit from 8 to $15 \mathrm{~h}$ is lower than the amount obtained from 2 to $8 \mathrm{~h}$. Such phenomenon occurred because most of the dissolved wax from both the blank and SN3-treated samples was deposited on the cold finger during the first $8 \mathrm{~h}$, which lead to a reduction in wax content later on from 8 to $15 \mathrm{~h}$. However, there is a difference between the environment when conducting laboratory experiments and the environment in the oil field where the wax deposition increases regularly due to more and more paraffin wax being deposited from the fresh crude oil onto the hydrocarbon pipeline, providing a more severe wax deposition upon the cold surface (Theyab 2017). Furthermore, the thickness of the deposited layer increases with the residence time and then acts as a thermal insulation which reduces the loss of heat energy from the bulk oil to the cold surface (Sanjay et al. 1995). Consequently, this lowers the availability of wax crystals for further deposition.

\subsubsection{Effect of cold finger temperature on wax deposition}

The amount of wax deposits was found to be inversely proportional to the cold finger temperature as shown in Fig. 12. 


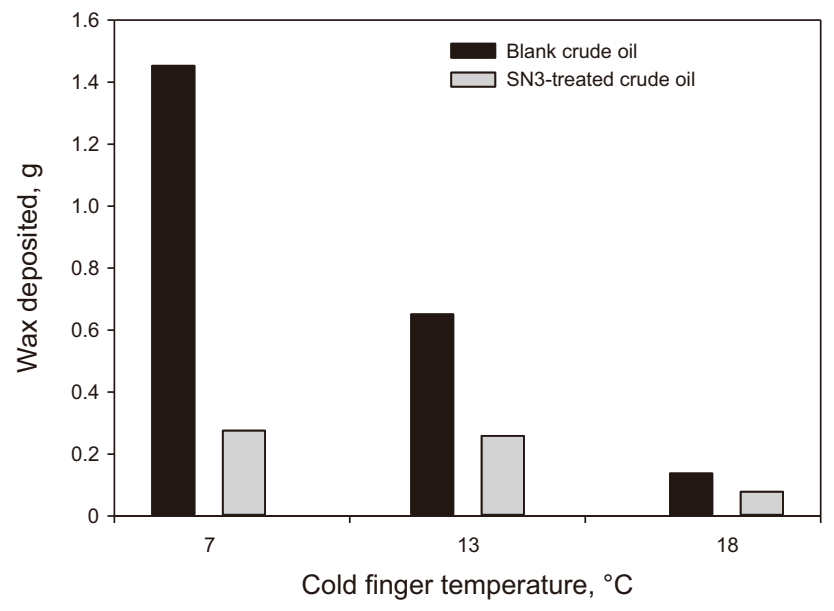

Fig. 12 Amount of wax deposits from blank and SN3-treated samples at different cold finger temperatures

This observation is concurrent with a slight deposition at the highest temperature, $18{ }^{\circ} \mathrm{C}$ for both blank and SN3treated samples. Based on our previous work analysed by design expert (Ridzuan et al. 2016a), the differential temperature $(\Delta T)$ was found to be the main factor affecting the wax deposition as far as the temperature was concerned. Equation (2) was applied in order to calculate the $\Delta T$,

$\Delta T=T_{\mathrm{o}}-T_{\mathrm{c}}$

where $\Delta T$ is the differential temperature between the warm oil and cold finger temperature (in ${ }^{\circ} \mathrm{C}$ ); $T_{\mathrm{o}}$ is the temperature of bulk oil in vessel and $T_{\mathrm{c}}$ is the temperature of cold finger, both expressed in ${ }^{\circ} \mathrm{C}$.

It is seen that the amount of wax deposit increases as the $\Delta T$ increases. At a constant $T_{\mathrm{o}}, 53{ }^{\circ} \mathrm{C}$, the highest amount of wax deposits was collected from both blank and SN3treated samples when the $T_{\mathrm{c}}$ was set at $7{ }^{\circ} \mathrm{C}$. However, only an insignificant amount ( 0.14 and $0.08 \mathrm{~g}$ ) of wax deposits was collected at the $18{ }^{\circ} \mathrm{C}$ (Fig. 13).

Presumably, it is believed that these phenomena are due to the increase in the precipitating ability and the decrease in the dissolving ability of components in the crude oil. Apart from that, the potential of the wax molecules to precipitate on the cold surface increased and the driving force of the wax molecules' diffusion from the bulk oil to the cold surface is strengthened predominantly when the $T_{\mathrm{c}}$ is $7{ }^{\circ} \mathrm{C}$. Moreover, as $T_{\mathrm{c}}$ decreases, the number of heavier $n$-paraffin molecules dissolved in the bulk oil increases and the diffusion of wax molecules to the gel layer increases. This is thought to lead to an increase in the hardness and variation of deposit layer. Overall, the increase in the amount of wax deposits is stimulated by the increase in the thermodynamic driving force (Jennings and Weispfennig 2005).

In this study, the differences in wax deposits due to the $\Delta T$ could be related to the basis of the classical Fick's mass

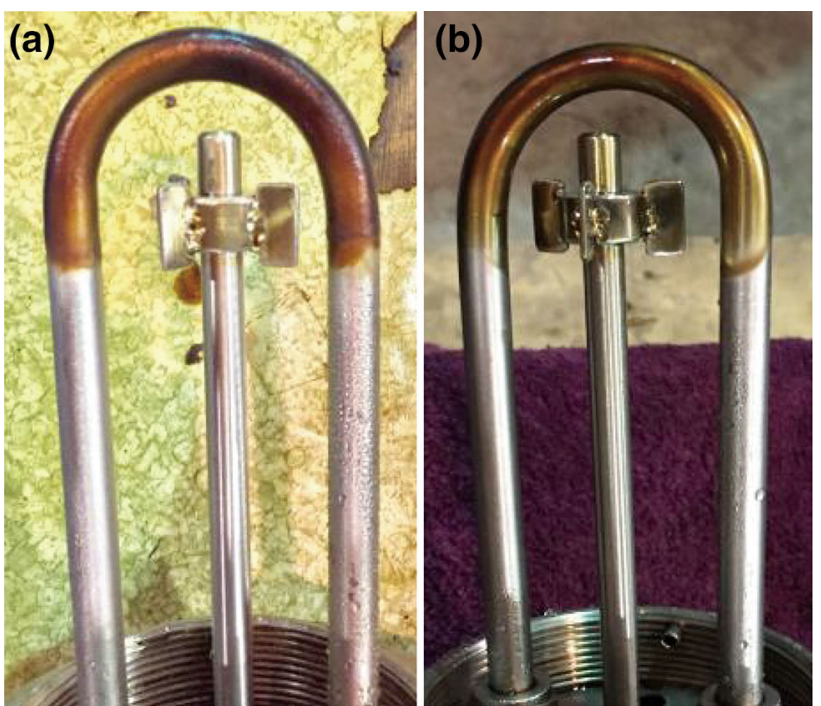

Fig. 13 Comparison between the physical appearances of the wax deposited on blank and treated samples at $18{ }^{\circ} \mathrm{C}$. a Blank sample at $18{ }^{\circ} \mathrm{C}$, b SN3-treated sample at $18{ }^{\circ} \mathrm{C}$

diffusion law as the formation of the wax deposits relies on the thermal gradient affected by the $T_{\mathrm{c}}$. When $T_{\mathrm{c}}$ is low, both the radial temperature gradient and the concentration gradient increased which ultimately produced mass transfer of dissolved wax towards the cold surface and thus results in deposition of wax (Zhang et al. 2010). Wax deposition happens only when the $\Delta T$ is larger than the critical temperature difference. Hence, in order for wax deposition to occur, a critical temperature difference between the cold finger $\left(T_{\mathrm{c}}\right)$ and the crude oil $\left(T_{\mathrm{o}}\right)$ must exist. Nonetheless, the wax deposition will not occur as long as the operating temperature remains above the WAT.

\subsubsection{Effect of rotation rate on wax deposition}

Both the blank and SN3-treated samples were analysed at a rotation rate of 200, 400 and $600 \mathrm{rpm}$ as shown in Fig. 14.

It is observed that both samples experienced the highest PIE at $400 \mathrm{rpm}$. From the physical appearance of wax deposited from SN3-treated sample in Fig. 15b, a small amount of wax was scattered on the cold finger in a less adhesive form. On the contrary, the wax deposited from blank sample showed a more organized deposition pattern (Fig. 15a). This observation is in agreement with the statement made previously by Kelland (2014) that an effective wax inhibitor is able to create weaker and softer deposits which are more susceptible to be sloughed off by shear forces in the flow field.

The amount of wax deposit increases as the rotation rate increases within the range of $200-400 \mathrm{rpm}$. At $400 \mathrm{rpm}$, the SN3-treated sample exhibits the most ideal condition to inhibit wax deposition, resulting in $82.7 \%$ of PIE which is 


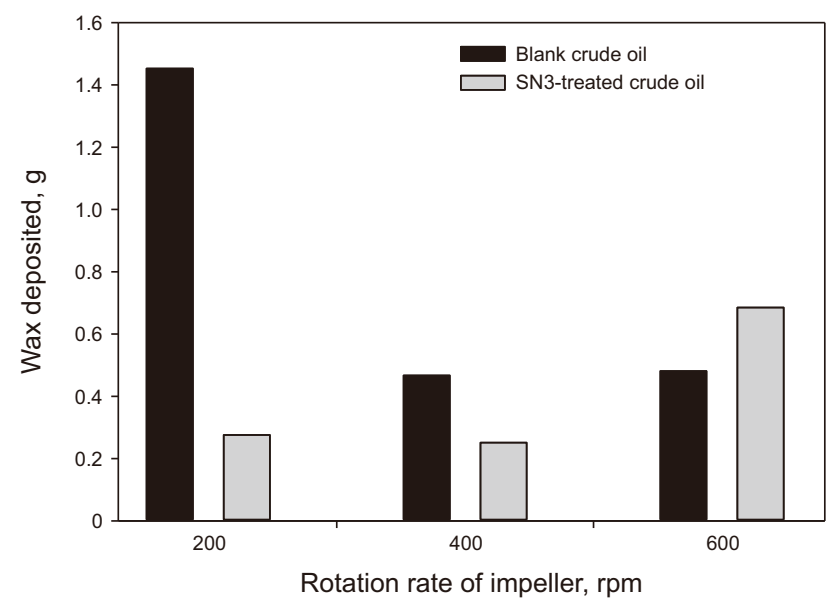

Fig. 14 Amount of wax deposits from blank and SN3-treated samples at different rotation rates
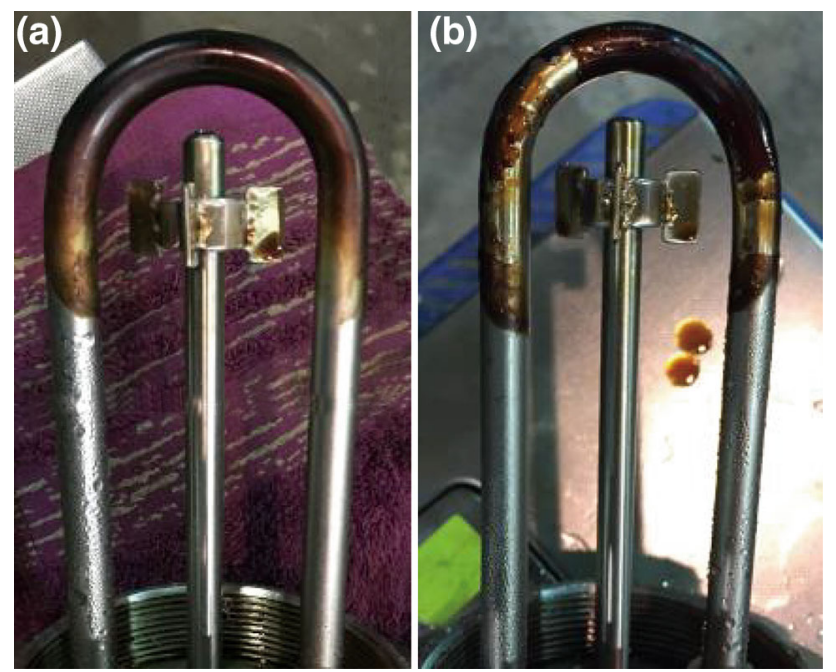

Fig. 15 Physical appearance of wax deposits from blank (a) and SN3treated (b) sample at $400 \mathrm{rpm}$

slightly higher than the $82.6 \%$ of PIE obtained during the optimization of $200 \mathrm{ppm}$ of $\mathrm{SiO}_{2}$ nanoparticles. However, the performance of $\mathrm{SN} 3$ deteriorated as the amount of wax deposits obtained at $600 \mathrm{rpm}$ increased slightly than that of the untreated sample. The present analysis can be observed in the previous work which demonstrated the existence of a similar plot between the amount of wax deposits and rotation rate (Ridzuan et al. 2015). At a rotation ranging from 200 to $400 \mathrm{rpm}$, it is observed that the effect of rotation possesses a crucial role in wax deposits as it has a directly proportional relationship with the amount of wax deposited.

However, the mechanism is different at a rapid rotation rate, whereby the amount of wax deposits oddly increased at $600 \mathrm{rpm}$. This is contrary to the majority of results reported in the literature which show that wax deposits decrease with a higher rotation rate. This phenomenon was attributed to a few reasons: (1) shear thickening behaviour, (2) variation in the untreated wax deposit with reference to the shear and (3) amount of entrained crude oil in the wax deposits. Once the optimal rotation rate is exceeded, the wax content in the crude oil started to increase due to the shear thickening behaviour of the fluid which results from a highly viscous liquid (Ridzuan et al. 2015).

Generally, at a rapid rotation rate, it will reduce the amount of entrained crude oil and hence lower the weight of wax deposits. This phenomenon does not relate to the performance of wax inhibitors but is partially affected by the rotation rate that causes a variation of the amount of entrained crude oil in the wax deposits. This causes the PIE to be uncertain due to the variation in the untreated deposit reference with shear which exists at different rotation conditions (Jennings and Weispfennig 2005). Thus, repeatability is fundamental and more effort is required to ensure the reliability of results.

\section{Conclusions}

A comparative study of the effect of surfactant and surfactant/nanoparticle blend on wax deposition tendencies was investigated using cold finger analysis under a static simulation. The key findings are:

1. With the sole use of $400 \mathrm{ppm}$ surfactants, the silanebased surfactant (S3), as wax inhibitor candidate, showed the highest PIE up to $53.9 \%$ while the biosurfactant (S1) offered the lowest PIE of $17.4 \%$ as compared to the scenario when surfactants were not added.

2. The addition of $400 \mathrm{ppm}$ of $\mathrm{SiO}_{2}$ nanofluid into all the primary surfactant-treated crude oil (400 ppm) resulted in superior PIE performance, of which, the silanebased surfactant/nanoparticles blends (SN3)-treated crude oil still remained providing the highest PIE up to $81 \%$.

3. A slight increment on PIE (to 82.6\%) was obtained when the concentration of $\mathrm{SiO}_{2}$ nanofluid in $\mathrm{SN} 3$ was reduced from 400 to $200 \mathrm{ppm}$ in an optimal load ratio (3:1) of surfactant and nanoparticles.

4. The amount of wax deposits with SN3 (400 ppm) increased with the residence time and attain a maximum value $(1.15 \mathrm{~g})$ when the residence time reached $15 \mathrm{~h}$ while lowest $(0.27 \mathrm{~g})$ at $2 \mathrm{~h}$.

5. At a fixed concentration $(400 \mathrm{ppm})$ of $\mathrm{SN} 3$, the temperature gradient from the oil to the cold finger temperature $\left(T_{\mathrm{c}}\right)$ was found to increase the wax deposition by $71 \%$ (from 0.08 to $0.27 \mathrm{~g}$ ) when $T_{\mathrm{c}}$ is at $7{ }^{\circ} \mathrm{C}$ compared to $18{ }^{\circ} \mathrm{C}$. 
6. The amount of wax deposits treated by SN3 (400 ppm) decreased with the rotation rate of impeller (PIE up to $82.7 \%)$, with the lowest value $(0.25 \mathrm{~g})$ obtained at $400 \mathrm{rpm}$, but rose at faster rotation.

Acknowledgements The authors wish to thank UCSI University and the Universiti Malaysia Pahang for their continuous support on this research. We would like to extend sincere thanks to Ms. Donna Zhi from RunHe Co. Ltd. for her ongoing support, MPOB for providing the chemicals and Petronas Penapisan Terengganu for contributing the crude oil samples. The authors would also like to extend their gratitude to Lion Corporation (Tokyo, Japan) for supplying the cationic Gemini surfactant used in this work.

Open Access This article is distributed under the terms of the Creative Commons Attribution 4.0 International License (http://creative commons.org/licenses/by/4.0/), which permits unrestricted use, distribution, and reproduction in any medium, provided you give appropriate credit to the original author(s) and the source, provide a link to the Creative Commons license, and indicate if changes were made.

\section{References}

Banerjee S, Kumar R, Mandal A, Naiya TK. Use of a novel natural surfactant for improving flowability of Indian heavy crude oil. Pet Sci Technol. 2015;33(7):819-26. https://doi.org/10.1080/ 10916466.2015.1014961.

Bello OO, Fasesan SO, Teodoriu C, Reinicke KM. An evaluation of the performance of selected wax inhibitors on paraffin deposition of Nigerian crude oils. Pet Sci Technol. 2006;24(2):195-206. https://doi.org/10.1081/LFT-200044504.

Binks BP, Whitby CP. Nanoparticle silica-stabilised oil-in-water emulsions: improving emulsion stability. Colloids Surfaces A Physicochem. 2005;253(1):105-15. https://doi.org/10.1016/j.col surfa.2004.10.116.

Chala GT, Sulaiman SA, Japper-Jaafar A. Flow start-up and transportation of waxy crude oil in pipelines-a review. J NonNewton Fluid Mech. 2018;251:69-87. https://doi.org/10.1016/j. jnnfm.2017.11.008.

Chi Y, Daraboina N, Sarica C. Investigation of inhibitors efficacy in wax deposition mitigation using a laboratory scale flow loop. AIChE J. 2016;62(11):4131-9. https://doi.org/10.1002/aic.15307.

Churaev NV, Ershov AP, Esipova NE, Hill RM, Sobolev VD, Zorin ZM. Application of a trisiloxane surfactant for removal of oils from hydrophobic surfaces. Langmuir. 2001;17(5):1349-56. https://doi.org/10.1021/la000864y.

Frigaard IA, Paso KG, de Souza Mendes PR. Bingham's model in the oil and gas industry. Rheol Acta. 2017;56(3):259-82. https://doi. org/10.1007/s00397-017-0999-y.

Ganeeva YM, Yusupova TN, Romanov GV. Waxes in asphaltenes of crude oils and wax deposits. Pet Sci. 2016;13(4):737-45. https:// doi.org/10.1007/s12182-016-0111-8.

García MDC. Crude oil wax crystallization: the effect of heavy $n$ paraffins and flocculated asphaltenes. Energy Fuels. 2000;14(5):1043-8. https://doi.org/10.1021/ef0000330.

Ghannam MT, Hasan SW, Abu-Jdayil B, Esmail N. Rheological properties of heavy \& light crude oil mixtures for improving flowability. J Pet Sci Eng. 2012;81:122-8. https://doi.org/10. 1016/j.petrol.2011.12.024.

Gu X, Zhang F, Li Y, Zhang J, Chen S, Qu C, Chen G. Investigation of cationic surfactants as clean flow improvers for crude oil and a mechanism study. J Pet Sci Eng. 2018;164:87-90. https://doi. org/10.1016/j.petrol.2018.01.045.

Jennings DW, Weispfennig K. Effects of shear and temperature on wax deposition: coldfinger investigation with a Gulf of Mexico crude oil. Energy Fuels. 2005;19(4):1376-86. https://doi.org/10. 1021/ef049784i.

Kelland MA. Production chemicals for the oil and gas industry. 2nd ed. Florida: CRC Press; 2014.

Koroleva MY, Gorbachevski OS, Yurtov EV. Paraffin wax emulsions stabilized with polymers, surfactants, and nanoparticles. Theor Found Chem Eng. 2017;51(1):125-32. https://doi.org/10.1134/ S0040579516060087.

Kumar L, Paso K, Sjöblom J. Numerical study of flow restart in the pipeline filled with weakly compressible waxy crude oil in nonisothermal condition. $\mathrm{J}$ Non-Newton Fluid Mech. 2015;223:9-19. https://doi.org/10.1016/j.jnnfm.2015.05.002.

Kumar S, Mahto V. Emulsification of Indian heavy crude oil using a novel surfactant for pipeline transportation. Pet Sci. 2017;14(2):372-82. https://doi.org/10.1007/s12182-017-0153-6.

Lei Y, Han S, Zhang J, Bao Y, Yao Z, Xu Y. Study on the effect of dispersed and aggregated asphaltene on wax crystallization, gelation, and flow behavior of crude oil. Energy Fuels. 2014;28(4):2314-21. https://doi.org/10.1021/ef4022619.

Li H, Zhang J, Song C, Sun G. The influence of the heating temperature on the yield stress and pour point of waxy crude oils. J Pet Sci Eng. 2015;135:476-83. https://doi.org/10.1016/j.petrol. 2015.10.010.

Lira-Galeana C, Hammami A. Wax precipitation from petroleum fluids: a review. In: Yen TF, Chilingarian GV, editors. Asph. New York: Elsevier; 2000. p. 557-608. https://doi.org/10.1016/ S0376-7361(09)70292-4.

Machado ALC, Lucas EF. Poly(ethylene-co-vinyl acetate) (eva) copolymers as modifiers of oil wax crystallization. Pet Sci Technol. 1999;17(9-10):1029-41. https://doi.org/10.1080/ 10916469908949763

Maithufi MN, Joubert DJ, Klumperman B. Application of gemini surfactants as diesel fuel wax dispersants. Energy Fuels. 2011;25(1):162-71. https://doi.org/10.1021/ef1006287.

Norrman J, Solberg A, Sjöblom J, Paso K. Nanoparticles for waxy crudes: effect of polymer coverage and the effect on wax crystallization. Energy Fuels. 2016;30(6):5108-14. https://doi. org/10.1021/acs.energyfuels.6b00286.

Paso KG, Fogler HS. Influence of $n$-paraffin composition on the aging of wax-oil gel deposits. AIChE J. 2003;49(12):3241-52. https:// doi.org/10.1002/aic.690491223.

Quan Q, Gong J, Wang W, Gao G. Study on the aging and critical carbon number of wax deposition with temperature for crude oils. J Pet Sci Eng. 2015;130:1-5. https://doi.org/10.1016/j. petrol.2015.03.026.

Paramashivaiah BM, Rajashekhar CR. Studies on effect of various surfactants on stable dispersion of graphene nano particles in simarouba biodiesel. IOP Conf Ser Mater Sci Eng. 2016;149(1):12083.

Ridzuan N, Adam F, Yaacob Z. Effects of shear rate and inhibitors on wax deposition of malaysian crude oil. Orient $\mathrm{J}$ Chem. 2015;31(4):1999-2004.

Ridzuan N, Adam F, Yaacob Z. Screening of factor influencing wax deposition using full factorial experimental design. Pet Sci Technol. 2016a;34(1):84-90. https://doi.org/10.1080/10916466. 2015.1122625.

Ridzuan N, Adam F, Yaacob Z. Evaluation of the inhibitor selection on wax deposition for Malaysian crude oil. Pet Sci Technol. 2016b;34(4):366-71. https://doi.org/10.1080/10916466.2015. 1127971. 
Sanjay M, Simanta B, Kulwant S. Paraffin problems in crude oil production and transportation: a review. SPE Prod Facil. 1995;10(01):50-4. https://doi.org/10.2118/28181-PA.

Song $\mathrm{X}$, Yin $\mathrm{H}$, Feng $\mathrm{Y}$, Zhang $\mathrm{S}$, Wang $\mathrm{Y}$. Effect of $\mathrm{SiO}_{2}$ nanoparticles on wax crystallization and flow behavior of model crude oil. Ind Eng Chem Res. 2016;55(23):6563-8. https://doi. org/10.1021/acs.iecr.6b00836.

Theyab MA. Study of fluid flow assurance in hydrocarbon production: investigation wax mechanisms. Ph.D. thesis [dissertation on the Internet]. London: University of London South Bank; 2017. http://researchopen.lsbu.ac.uk/1855/.

Wang F, Zhang D, Ding Y, Zhang L, Yang M, Jiang B, et al. The effect of nanohybrid materials on the pour-point and viscosity depressing of waxy crude oil. Chin Sci Bull. 2011;56(1):14-7. https://doi.org/10.1007/s11434-010-4174-4.

Wang Z, Yu X, Li J, Wang J, Zhang L. The use of biobased surfactant obtained by enzymatic syntheses for wax deposition inhibition and drag reduction in crude oil pipelines. Catalysts. 2016;6(5):61. https://doi.org/10.3390/catal6050061.

Yang F, Paso K, Norrman J, Li C, Oschmann H, Sjöblom J. Hydrophilic nanoparticles facilitate wax inhibition. Energy Fuels. 2015;29(3):1368-74. https://doi.org/10.1021/ef502392g.

Zhang Y, Gong J, Wu H. An experimental study on wax deposition of water in waxy crude oil emulsions. Pet Sci Technol. 2010;28(16):1653-64. https://doi.org/10.1080/109164609030 96822 . 